\title{
Adsorption properties of benzene vapors on activated carbon from coke and asphalt
}

\author{
Nagima Khudayberganova ${ }^{1}$, Abdumalik Rizaev $^{1}$, and Eldor Abduraxmonov ${ }^{2 *}$ \\ ${ }^{1}$ Tashkent State Transport University, Tashkent, Uzbekistan \\ ${ }^{2}$ Institute of General and Inorganic Chemistry of the Academy of Sciences of the Republic of \\ Uzbekistan, Tashkent, Uzbekistan
}

\begin{abstract}
The industry produces a variety of wastes in production processes. This has a negative impact on the state of ecological balance. Today, in the oil industry, many different types of oil waste are accumulated as reserves. Focusing them on targeted production is one of the most pressing issues today. The use of a high-vacuum adsorption device is important in producing adsorbents from coke and asphalt from residual oil products and in the complete determination of the sorption properties of the obtained adsorbents. Benzene and toluene adsorption isotherms, the sorption volume, and properties of the new adsorbent can be described in detail by studying the adsorption heat.
\end{abstract}

\section{Introduction}

At present, the world economy is focused on developing processes that deepen oil refining [1].

One of the most reliable ways to deepen oil refining is the production of petroleum coke [2]. The coking process allows the processing of various types of oil residues (resins, semiresins, pyrolysis resins, cracking residues, selective cleaning extracts, asphalt, etc.) [3].

Activation of carbon-containing substances consists of their thermal treatment, which results in the formation of many holes, cracks, fissures. It increases the surface area per unit mass of the hole mass. [4, 5].

The activation ability of carbon materials depends in many respects on the proportion of volatile components. For example, it is difficult to activate graphite due to its low amount. As the number of volatile components increases, the reactivity of carbon-containing materials increases. However, high reactivity leads to a decrease in the activation level, for example, in coal [5].

Among the practical methods of activating carbon-containing materials, chemical activation can be distinguished, which is traditionally divided into three types [6]:

- chemical activation of the solid phase;

- activation of steam gas by treatment with hot steam or oxidation with active gases;

*Corresponding author: eldor8501@gmail.com 
- combined activation.

New effective methods of activating carbon-containing substances under mild conditions through their thermochemical changes are currently being explored. One of the less-studied promising areas is ozonation [7]. Ozone is carried out in flow gas conditions at a temperature of $20^{\circ} \mathrm{C}$, in the gas and liquid phases of the ozone concentration $2-5 \%$.

The advantage of steam-gas activation of petroleum coke is that with this activation method, a clean product is obtained that does not require additional processing, does not emit harmful wastewater and waste into the atmosphere, does not require the presence of activators (especially water vapor) and low cost. And the cheapness of the finished product [8-11].

Raxmatkariev G.U. et al. conducted calorimetric studies on the adsorption of polar and nonpolar molecules on surface surfaces and microporous adsorbents [12-23].

The country conducted numerous research for obtaining new types of residual oil adsorbents and their use in the practice of waste water purification in the oil industry, the study of the sorption properties of a vacuum method [24-26].

\section{Methods}

The differential heat of adsorption was measured on the DAC 1-1 calorimeter in the TianKalve model. Adsorption isotherm was used in the determination of the volumetric method. The accuracy of the adsorption isotherm is $0.1 \%$, and the heat is up to $1 \%$ [27].

Benzene and toluene obtained as adsorbates were cleaned and dried under vacuum before use in sorption. Dissolved gases were removed until their vapor pressure was the same as the vapor pressure data given in the tables for pure benzene and toluene. It was then determined that it was consistent with the data presented in the literature.

The activated carbon sample from the studied coke and asphalt was adsorbed on benzene and toluene at $303 \mathrm{~K}$.

\section{Results and Discussion}

Activated carbon was obtained by pyrolysis using coke and asphalt. The fundamental study of the sorption properties of the obtained coal is based on the results obtained from a highvacuum sorption device. 
Table 1. Quantities characterizing the adsorption of benzene on the obtained coal adsorbent

\begin{tabular}{|c|c|c|c|c|c|c|}
\hline № & $\begin{array}{c}\text { a } \\
\text { (adsorption) }\end{array}$ & $\begin{array}{c}\text { P (relative } \\
\text { pressure) }\end{array}$ & $\begin{array}{c}\ln (p, p s) \\
\text { (logarithmic } \\
\text { pressure) }\end{array}$ & $\begin{array}{c}\tau \\
\text { (equilibrium } \\
\text { time) }\end{array}$ & $\begin{array}{c}Q_{d} \\
\text { (differential } \\
\text { heat) }\end{array}$ & $\begin{array}{c}\Delta S_{d} \\
\text { (entropy) }\end{array}$ \\
\hline 1 & 0.012 & 0.01 & -9.36 & 6.91 & 99.10 & -118.64 \\
\hline 2 & 0.033 & 0.02 & -8.50 & 2.60 & 87.00 & -105.49 \\
\hline 3 & 0.14 & 0.29 & -6.02 & 3.10 & 86.80 & -106.13 \\
\hline 4 & 0.21 & 0.40 & -5.70 & 2.40 & 74.90 & -86.03 \\
\hline 5 & 0.30 & 0.87 & -4.92 & 2.60 & 73.00 & -95.78 \\
\hline 6 & 0.46 & 1.81 & -4.19 & 2.70 & 76.90 & -117.22 \\
\hline 7 & 0.58 & 2.89 & -3.72 & 2.30 & 82.30 & -120.78 \\
\hline 8 & 0.68 & 4.23 & -3.34 & 2.40 & 76.70 & -110.25 \\
\hline 9 & 0.77 & 5.48 & -3.08 & 2.10 & 74.00 & -110.72 \\
\hline 10 & 0.89 & 6.98 & -2.84 & 1.90 & 75.68 & -113.39 \\
\hline 11 & 1.07 & 9.81 & -2.50 & 1.90 & 74.40 & -109.81 \\
\hline 12 & 1.26 & 13.08 & -2.21 & 1.88 & 71.80 & -102.96 \\
\hline 13 & 1.45 & 16.09 & -2.00 & 1.71 & 68.80 & -94.12 \\
\hline 14 & 1.63 & 19.53 & -1.81 & 1.66 & 65.40 & -81.54 \\
\hline 15 & 1.86 & 23.42 & -1.63 & 1.60 & 60.20 & -35.67 \\
\hline 16 & 2.08 & 27.40 & -1.47 & 1.24 & 36.69 & -1.49 \\
\hline 17 & 2.22 & 30.40 & -1.37 & 1.20 & 38.70 & -5.68 \\
\hline 18 & 2.39 & 34.50 & -1.24 & 1.29 & 38.70 & -0.29 \\
\hline 19 & 2.50 & 38.61 & -1.13 & 1.17 & 34.80 & 5.21 \\
\hline 20 & 2.67 & 44.70 & -0.98 & 1.38 & 34.80 & 6.79 \\
\hline 21 & 2.80 & 49.30 & -0.88 & 1.31 & 33.10 & 4.33 \\
\hline 22 & 2.91 & 55.10 & -0.77 & 1.37 & 35.80 & 1.10 \\
\hline 23 & 3.02 & 62.10 & -0.65 & 1.15 & 34.50 & 1.42 \\
\hline 24 & 3.15 & 71.70 & -0.51 & 1.47 & 35.00 & 0.56 \\
\hline 25 & 3.26 & 78.60 & -0.42 & 1.10 & 34.30 & 0.12 \\
\hline 26 & 3.36 & 84.20 & -0.35 & 1.70 & 34.80 & -1.60 \\
\hline 27 & 3.43 & 88.80 & -0.30 & 2.14 & 35.00 & -0.39 \\
\hline 28 & 3.56 & 94.70 & -0.23 & 2.46 & 33.80 & 0.23 \\
\hline 29 & 3.61 & 97.90 & -0.20 & 2.42 & 34.30 & 0.28 \\
\hline 30 & 3.67 & 101.80 & -0.16 & 2.49 & 33.60 & -1.60 \\
\hline 31 & 3.73 & 105.60 & -0.12 & 2.10 & 35.25 & -5.30 \\
\hline 32 & 3.79 & 109.70 & -0.08 & 2.18 & 35.66 & -5.89 \\
\hline 33 & 3.88 & 113.70 & -0.05 & 2.03 & 35.41 & -4.47 \\
\hline 34 & 3.90 & 118.80 & -0.02 & 2.35 & 34.61 & 53.60 \\
\hline & & & & & & \\
\hline & & & & & \\
\hline & & & & & & \\
\hline
\end{tabular}

Adsorption thermodynamics is studied by calculating the adsorption mechanisms of benzene adsorption on the obtained coal, the amount, strength, location, nature of the active centers, and energy adsorbent-adsorbate interaction. In benzene adsorption, the adsorption heat effect occurs both in the physical adsorption process and in the chemical adsorption (chemisorption) process. Heat is released as the adsorption of adsorbents on the adsorbents is an exothermic process. The difference between chemical adsorption and physical adsorption is that the amount of heat released during the sorption process is equal to or close to the thermal effect of chemical reactions. 


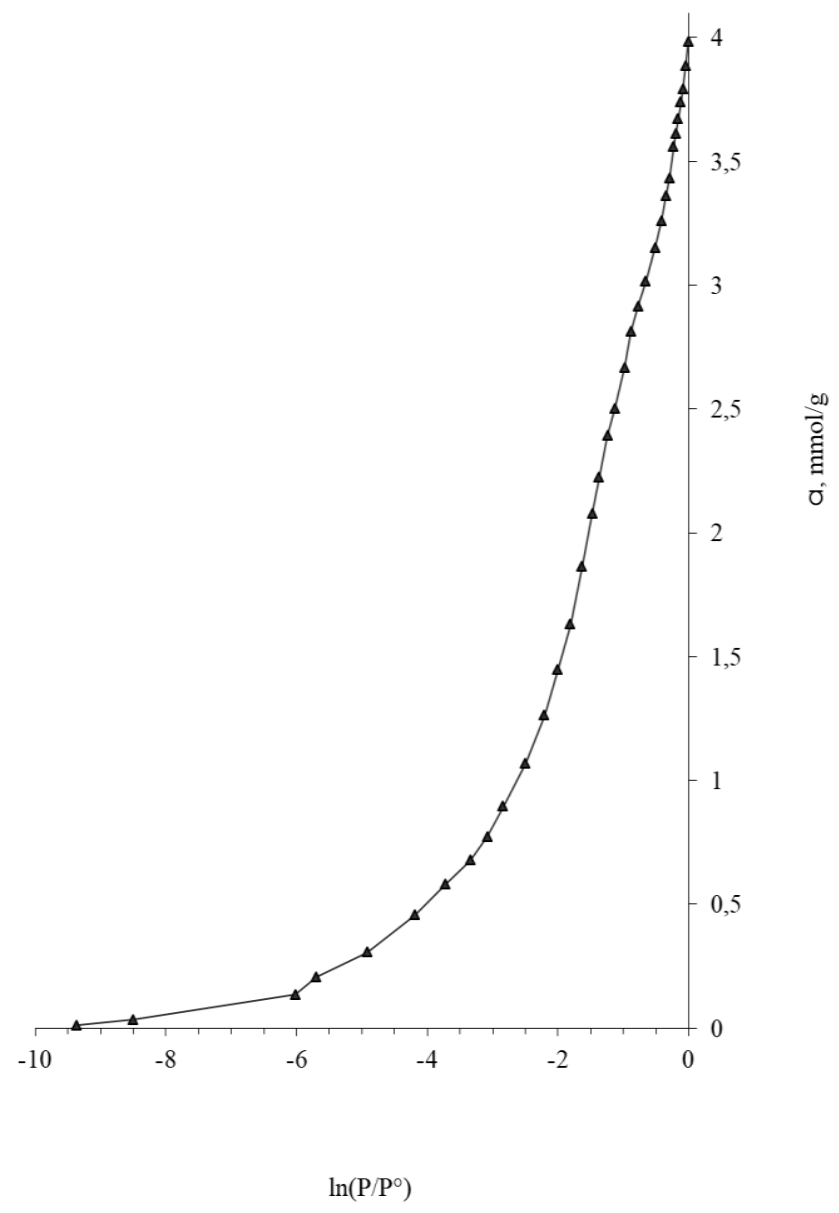

Fig. 1. A figure caption is always placed below the illustration. Short captions are centered, while long ones are justified. The macro button chooses the correct format automatically

The benzene adsorption isotherm is obtained from coal obtained from coke and asphalt at a temperature of $303 \mathrm{~K}$. As can be seen from the adsorption isotherm graph; the isotherm values are initially very small. At small values, benzene indicates an increase in the interior of the coal. We can observe a gradual increase in the isotherm graph after adsorption exceeds $0.5 \mathrm{mmol}, \mathrm{g}$. After this value, benzene molecules are slowly sorbed to the active surface surfaces of the coal. When the adsorption reaches $4 \mathrm{mmol}, \mathrm{g}$, benzene reaches saturation vapor pressure at $30^{\circ} \mathrm{C}$, and coal is saturated with benzene.

The differential heat of adsorption of benzene vapors on coke and asphalt-derived coal (KAOK) at a temperature of $303 \mathrm{~K}$ is given in Fig. 2. The adsorption heat of benzene in KAOK was $99.05 \mathrm{~kJ}, \mathrm{~mol}$ at $\mathrm{a}=0.06 \mathrm{~mol}, \mathrm{~kg}$ at the initial saturation. After that, the heat value of adsorption decreases slightly and reaches $\mathrm{Q}=82.46 \mathrm{~kJ}$, mol at a $=0.52 \mathrm{~mol}, \mathrm{~kg}$ The reason for the high heat at such small saturations is the formation of $n$-type p-complexes with benzene molecules and rare metal cations $\left(\mathrm{Me}^{\mathrm{n}+} \mathrm{C}_{6} \mathrm{H}_{6}\right)_{\mathrm{n}}$ in the carbon sample. Subsequently, a decrease in the adsorption differential heat value $\mathrm{a}=1.67 \mathrm{mmol}, \mathrm{g}$ to $\mathrm{Q}=$ $61.66 \mathrm{~kJ}$,mol was observed. 


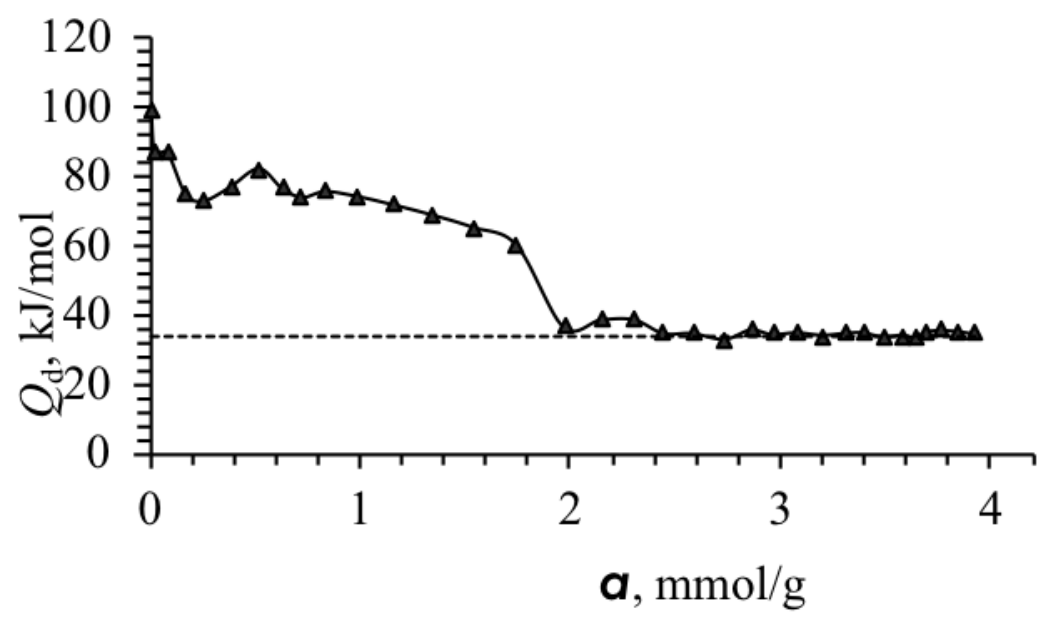

Fig. 2. Differential heat of adsorption of benzene vapors on coal from coke and asphalt at a temperature of 303K. Horizontal bar line Condensation heat of benzene vapor at $303 \mathrm{~K}$

In this saturation state, the electron acceptor formed in the activation state of coal (vapor-gas method) corresponds to the field of formation of n-type p-complexes $\left(\mathrm{C}_{n}^{+} \mathrm{C}_{6} \mathrm{H}_{6}\right)$ due to acid-base interaction of carbon atoms with benzene molecules. Such a decrease in the differential heat values $\pi$ of adsorption is explained by the adsorption on the empty micro- and mesocytes in the adsorbent and a decrease in the adsorption energy as it becomes saturated. Subsequent adsorption values occur when the adsorption condensation heat value of benzene vapors is close to $33.8 \mathrm{~kJ}$, mol.

Because the porosity and surface dimensions of coal adsorbent pores are small relative to benzene, sunken is formed in such pores. In these mens the adsorbent vapors condense at pressures below the flat surface saturation pressure $\left(\mathrm{P}_{\mathrm{s}}\right)$. At this time, the walls of the capillaries of the adsorbent initially form polymolecular layers, which accumulate and become a liquid that moistens the capillary and fills it. It should also be noted that capillary condensation occurs not under the influence of adsorption forces but under the influence of the force of attraction of vapor molecules to the spherical surface of the liquid.

The value of adsorption entropy describes the state of motion of a certain amount of absorbed adsorbate molecules in the adsorbent. The entropy curve of the KAOK-benzene system has a wavy appearance following the adsorbent saturation values (Fig. 3). The minimum value of the integral entropy value, expressed in molar values of adsorption, in the formation of $\mathrm{p}$-complexes, the negative value of entropy was $\Delta \mathrm{S}=-120.45 \mathrm{~J}$,(mol K). Then in the KAOK -benzene system, the negative values of adsorption entropy exceeded the minimum at $1.67 \mathrm{mmol}, \mathrm{g} \Delta \mathrm{S}=-64.65 \mathrm{~J},(\mathrm{~mol} \mathrm{~K})$. From these cases, the benzene molecules absorbed into the adsorbent form a motionless, i.e., solid-state entropy. Then twice more after $2 \mathrm{mmol}, \mathrm{g}$ it passes the minimum at $\Delta \mathrm{S}=-0 \mathrm{~J},(\mathrm{~mol} \mathrm{~K})$. 


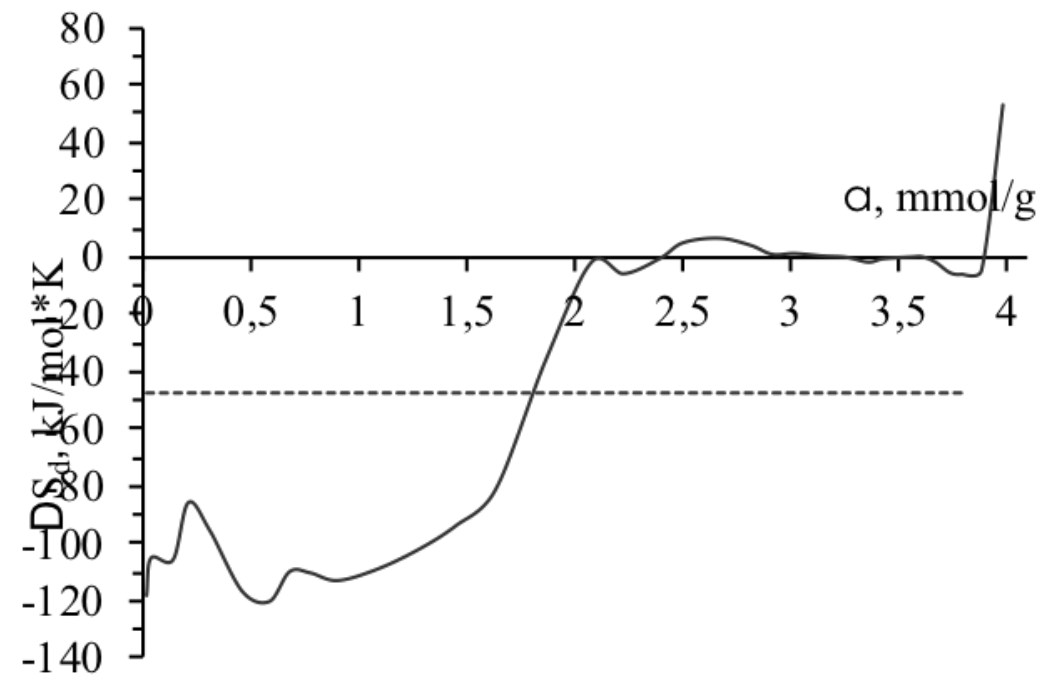

Fig. 3. Molar integral entropy of adsorption of benzene vapors on KAOK at a temperature of $303 \mathrm{~K}$

After $2 \mathrm{mmol}, \mathrm{g}$, the motion of benzene molecules is equal to the motion of molecules in the liquid state due to capillary condensation in the adsorbent.

The dependence of the time of formation of the adsorption equilibrium on the adsorption was studied (Fig. 4).

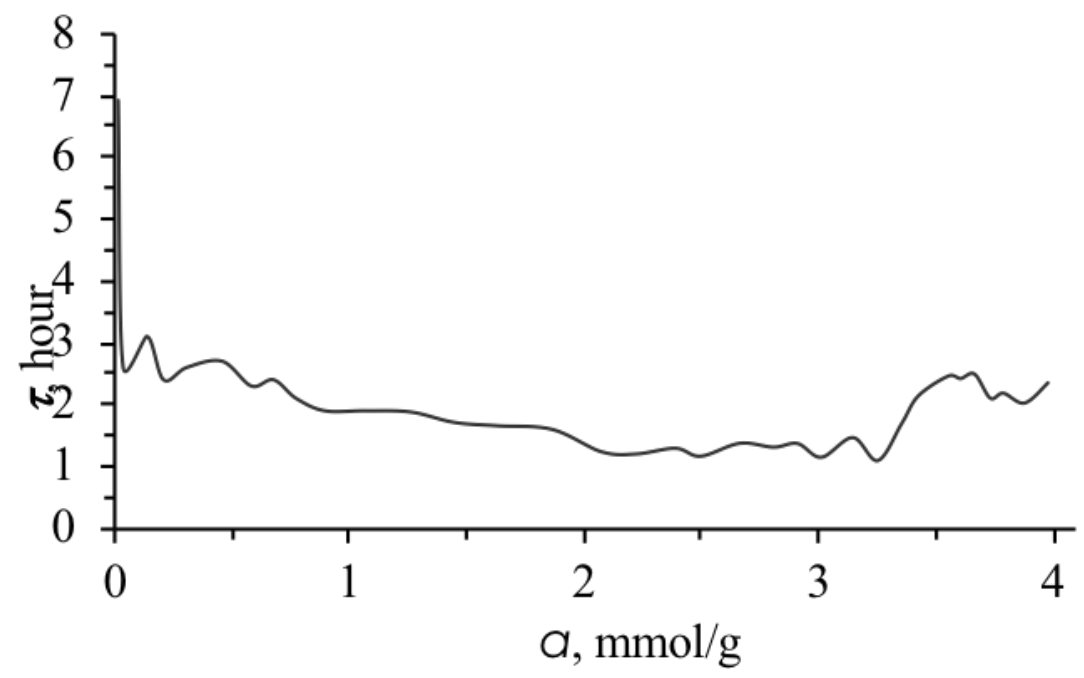

Fig. 4. Kinetics of adsorption of benzene vapors on KAOK at a temperature of $303 \mathrm{~K}$

Setting the adsorption equilibrium at the sites of formation of the first p-complexes of benzene adsorption in $\mathrm{KAOK}$ is $\mathrm{t} \approx 7$ hours. As the adsorption increases, the wavy appearance decreases to 2 hours. Adsorption was found to last from $t \approx 1$ hour to several minutes in the final saturation cases. Adsorption increases from $3.2 \mathrm{mmol}, \mathrm{g}$ to $t \approx 2.5 \mathrm{~h}$, in which case we can explain the time taken for the adsorbate-adsorbate interaction.

The obtained adsorbent was tested and positively evaluated at two major oil refineries of the Republic. 


\section{Conclusion}

Coal adsorbent was obtained from coke and asphalt from residual oil products, and its adsorption properties were studied. The fact that the adsorption isotherm and differential temperatures are initially high indicates that adsorption is taking place in the metal cations and pores in the active centers of this adsorbent. This is also proved by the values of adsorption entropy and equilibrium time. The main feature of the obtained adsorbent is the production of products for industry using the environmentally hazardous waste of oil.

\section{References}

1. Technical and economic aspects of the application of non-catalytic processes for deep processing of residues. Analytical material. - M .: TsNIIT-Eneftekhim,. p 109. (2012).

2. Sunyaev Z.I. Production, upgrading and application of petroleum coke. Z.I. Sunyaev. M .: Chemistry,. p 296. (1973)

3. Gaskarov N.S. New in the technology of the delayed coking process. That. overview. Ser. Oil refining, N.S. Gaskarov, V.V. Verba, R.N. Gimaev - Moscow: TsNIITEneftekhim, p 76. (1971).

4. Akhmetov S.A. Technology of oil, gas and solid fossil fuel processing: textbook, S.A. Akhmetov, M.Kh. Ishmiyarov, A.A. Kaufman. -SPb .: Nedra,. p 832. (2009)

5. Kinle X. Active carbons and their industrial application, Kinle X., Ba-der E.-L .: Chemistry,. p 216. (1984)

6. Butyrin G.M. Highly porous carbon materials, G.M. Butyrin. -M, Chemistry, p 192. (1976).

7. Emelyanova G.I. Oxidation of brown coal by ozone, G.I. Emelyanova, L.E. Gorlenko, E.H. Grigorieva, A. Yankovska, V.V. Lunin, Collection of the 1st International Conference: Carbon: Fundamental Problems of Science, Materials Science, Technology. p 91. (2002)

8. Savelyeva Yu.R. Obtaining active coal from the cedar nut shell, Yu.R. Savelyeva, A.M. Kryazhev, M.S. Bogomolov, B.JL Ivasenko, V.T. Novikov., Chemistry of plant materials. (4). p 61.(2003)

9. Yuriev Yu.L. Wood pyrolysis, IO.J1. Yuryev - Yekaterinburg: Ural State Forestry Academy,. p 99. (1997).

10. Andreas Q. Structural changes in activated wood based carbons, correlation between specific surface area and localization o molecularized pores, H. Andreas and other., Holzforschung. 60. (1). p. 85. (2006).

11. SICH H.B. Porosity and sorption properties of active carbons from anthracite obtained by air-vapor activation, N.V. Sych et al., Journal of Applied Chemistry.79. (4). p. 565. (2006).

12. Mamajonova M.A., Salikhanova D.S., Abdurakhmonov E.B., Ismoilova M.A. Adsorption Isotherm, Differential Heat, Entropy and Thermokinetics of Benzene Vapor in Pakistan BentoniteInternational Journal of Materials and Chemistry, 10 (2):pp 23-26 DOI: 10.5923,j.ijmc.20201002.02. (2020).

13. Ergashev, O.K., Rakhmatkarieva, F.G., Abdurakhmonov, E.B., and Mamazhonova, M.A. Ion-molecular complexes in nanostructured zeolite nitrite-sodalite. Universum: Chemistry and Biology, (9), pp 14-17. (2018).

14. Abdurakhmonov Eldor, Rakhmatkariev Gairat, Rakhmatkarieva Feruza, Ergashev Oybek. Adsorption-microcalorimetric investigation of benzene condition and distribution in the zeolite LiY, Austrian Journal of Technical and Natural Sciences. 
January - February, 1-2, , pp.72-76.(2018).

15. Muminov S.Z., Kurbonov S.D., Ergashev O.K.. The effect of thermal dehydration of polyhydroxyaluminum montmorillonite on the adsorption of carbon tetrachloride. Sorption and chromatographic processes, 14 (6). (2014).

16. Muminov, S. Z., Voymatov, I. M., Ergashev, O. K., \& Khandamov, D. A. Heat of adsorption of pyridine vapor on sodium and polyhydroxyaluminium montmorillonites. Sorption and chromatographic processes, 13 (4). (2013).

17. Rakhmatkariyeva F.G., Abdurakhmonov E.B., Yakubov Y.Y. Volumetric Analysis of Benzene Vapor Adsorption on LiLSX Zeolite in a High Vacuum Adsorption Device, International Journal of Advanced Science and Technology 29, (8), , pp 3442-3448. (2020).

18. Abdurakhmonov E.B., Rakhmatkarieva F.G., Ergashev O.K., Ochilov G.M. Energetic Characteristics Of The Process Of Adsorption Of Benzene In Zeolites NaX And NaY, International Journal of Future Generation Communication and Networking, 13, (4), pp. 246-252.(2020),

19. Abdurakhmonov Eldor Baratovich, Rakhmatkarieva Firuza Gayratovna, Ergashev Oybek Karimovich Determination of ammonia's adsorption properties in NaLSX zeolite by calorimetric method, "International Journal of Materials and Chemistry", 10 (2), pp 17-22 (2020)

20. Rakhmatkariev G.U., Usmanova F.G. Abdurakhmonov E.B. Isotherm and differential heats of adsorption of benzene in zeolite LiY, Uzbek chemical journal, (Tashkent), 1. pp 13-16. (2013)

21. Akhmedov U.K., Rakhmatkarieva F.G., Kokhkharov M.Kh., Abdurakhmonov E.B. $\mathrm{CaA}$ zeolithiga carbonate anhydride adsorption of energetics, Composite materials 2. pp 97-100. (2019)

22. Ergashev O.K., Kokhkharov M.Kh., Abdurakhmonov E.B. CaA (M-22) zeolitide carbonate anhydride gases and adsorptionsining energetics, FarDU Ilmiy Khabarlar (5). pp 36-40. (2019)

23. Rakhmatkarieva F.G., Abdurakhmonov E.B., Khudoiberganov M.S. Energetics of ammonia adsorption in NaX zeolite, Universum: chemistry and biology , 6 (60), June 2019. pp. 39-42. (2019)

24. Ergashev O.K., Kokhkharov M.Kh., Abdurakhmonov E.B. Energy of adsorption of carbon dioxide in zeolite CaA, Universum: chemistry and biology: scientific journal. 7 (61) pp. 23-26. (2019)

25. Abdumalik Rizaev. Research methods of water purification from pollution with petroleum and petroleum products, International Journal of Psychosocial Rehabilitation, Vol. 24, Issue 08, 2020. p.5630-5634

26. Hudayberganova N.T.,Rizaev A.N., Musaev O.M.. Study of Benzene Vapor Adsortion in Adsorbents Based on Oil Waste, International Journal of Materials and Chemistry, 10 (2) pp 27-29 DOI: 10.5923,j.ijmc.20201002.03.(2020)

27. Hudayberganova N.T., Rizaev A.N., Hamidov B.N., Musaev O.M.. Benzol adsorbation on activated coal adsorbents, International Journal of Advanced Research in Science, Engineering and Technology. 6, (11), November 2019. pp.11609-11611. (2019).

28. Mentzen B.F., Rakhmatkariev G.U. Host, Guest interactions in zeolitic nonostructured MFI type materials, Complementarity of X-ray Powder Diffraction, NMR spectroscopy, Adsorption calorimetry and Computer Simulations, Узб. хим. журнал,.(6) pp 10-31. (2007) 